$\xi=$

\title{
The distribution and length size of corbicula fluminea (ETAK) in Sungai Pergau at Gunung Reng
}

\author{
Aweng Eh Rak ${ }^{1 *}$, Nur Fasihah Binti Ab Khalid²,Sharifah Aisyah Syed Omar ${ }^{3}$, \\ ${ }^{1,2,3}$ Faculty of Earth Science, Universiti Malaysia Kelantan, Jeli Campus Locked Bag No. 100, 17600 Jeli, Kelantan, Malaysia \\ *Corresponding author E-mail: aweng@umk.edu.my
}

\begin{abstract}
Corbicula fluminea (Bivalvia: Corbiculidae), locally known as "etak" which is the favorite freshwater clams in the Kelantan state. This study was conducted to study on Etak distribution in Sungai Pergau at Gunung Reng which is known as a recreational spot. As it is the favorite freshwater clam in the state, the data could be helpful in monitoring its presence and if in decline, remedial and replenishment could be introduced. The numbers, weight and the length measurement of C. fluminea were identified as C. fluminea parameters. In addition, water quality used (conductivity, $\mathrm{pH}$, turbidity, salinity, temperature, $\mathrm{DO}$ and nitrate) and types of substrate were also studied to identify the habitat characteristics that affect the distribution of this species. As there was no documentation of distribution and density of C. fluminea in Sg. Kelantan, it would be difficult to compare the density and distribution of "etak" in the others river in Kelantan. In total 166 individuals of $\mathrm{C}$. fluminea $(77 \mathrm{~g})$ found at middle streams with $11-12.5 \mathrm{~mm}$ in length. As the finding shows that, the distribution of $\mathrm{C}$. fluminea at Gunung Reng was not affected by water quality. In this study shows that the most substrate ranged from $0.25 \mathrm{~mm}$ and $0.71 \mathrm{~mm}$ which represent sand (sand-coarse and sand-fine). It is believed that the smaller substrates help to trap more suspended materials as food for C. fluminea and the harvesting activities reduce the time for the clams to grow mature with a larger size in length.
\end{abstract}

Keywords: Corbicula fluminea; etak; Gunung Reng; length size; substrates type

\section{Introduction}

C. fluminea is one of bivalve species which commonly named as Asian clam. This species can be found in the eastern Mediterranean, South East Asia, Africa and some place in eastern Australia (1). C. fluminea is viewed as one of the world's most invasive freshwater clam, having invaded North America, South America, Europe and northern Africa. It is used as fish bait and sold as "pygmy clam", or "golden clam" in North America and cause problems by overpopulated in the water channel. However, it is one of the popular foods and snacks in Kelantan which known as 'etak'. It can be prepared in many ways and sold in the wet market or roadside stalls in Kelantan $(2,3)$

Gunung Reng River is one of the well-known recreational spots in Kelantan and this activity may influence the distribution of $C$. fluminea in this area. Hence, this study aimed to study the distribution of $C$. fluminea in Pergau River at Gunung Reng River.

\section{Literature Review}

C. fluminea typically found with $25 \mathrm{~mm}$ in length and can reach $50-65 \mathrm{~mm}$ in length. It has an oval shape without elongated and deep on the hinge side. The outer layer of the shell has welldefined, thick growth rings and varied coloration. The older clams the darker colored periostracum can be. Typically, this clam is found buried within the top $10-15 \mathrm{~cm}$ of the substrate in $2 \mathrm{~m}$ to $40 \mathrm{~m}$ of water with highest densities occurring between $3-10 \mathrm{~m}$ depth. John (4)stated that the suitable substrate composition for $C$. fluminea was in $>40 \%$ fine sand, $<45 \%$ silt, and $8 \%$ organic content. Castaneda (5)mentioned that it is easy to colonize and shape thick neighborhood populations. Crepso, Dolbeth (6) state this bivalve species usually found in oxygenated waters and is intolerant to high salinity values, low $\mathrm{pH}$ and low calcium fixations. However, they also get a high reproductive ability and consequently make it more resilient and help them to recover quickly from events of catastrophic mortality (7). C. fluminea also act as the filter feeder and indirectly help to clear the water by removing broad quantities of planktonic food and fostering the distribution of macrophyte algae (7).

\section{Methodology/Materials}

\subsection{Study area}

The study area is located at Sungai Pergau in Gunung Reng River, Kelantan. The study area consists of 10 sampling points at $200 \mathrm{~m}$ along the river with a total of three stations (upstream, middle and downstream) and the sampling was repeated three times.

\subsection{Substrates composition}

The substrate sample from each station was retained for granulometric analysis (Rory et al., 2014) by using a mechanical sieve shaker. Next the substrate characteristic categorized according to the Wentworth Grain Size Chart. In sieve size of $2.36 \mathrm{~mm}$, the 
substrate was in category of pebbles (fine granules). While $1.18 \mathrm{~mm}, 0.71 \mathrm{~mm}, 0.50 \mathrm{~mm}, 0.25 \mathrm{~mm}$ and $0.125 \mathrm{~mm}$ was from sand which each of the stated sieve size was very coarse, coarse, medium, fine and very fine sand respectively. On other hand, silt and clay were from the sieve size of 0.045 and 0.02 respectively.

\subsection{Water Quality}

Six physical water quality parameters were measured by using YSI instrument, which were conductivity, $\mathrm{pH}$, temperature, DO, salinity. Turbidimeter used to measure turbidity. In addition, water sample has been collected at each point selected for collection of $C$. fluminea samples to analyze the concentration of nitrate at the laboratory.

\subsection{C. fluminea collection and measurement}

C. fluminea were collected by sieving the sediments through the sieve for Etak in size of $17.85 \mathrm{~m}^{2}$, at random point. At every point, the samples were taken triplicates to take the average value. The $C$. fluminea within each quadrat were handpicked and retained in marked zipper bags plastic. The conventional morphometric characteristics, which were, shell height (H- umbo to gape) and length (L-anterior to posterior margins of the shell) of each specimen measured to the nearest $0.1 \mathrm{~mm}$ using vernier caliper. The total shell length was used as a standard size measure for statistical adjustment of the measured variables (8).

\section{Results and Findings}

\subsection{Substrate's distribution}

Table 1 showed that a quite similar pattern of substrates weight $\%$ from downstream toward upstream. Right and middle side were composed around $40 \%-45 \%$ pebbles-fine granules, 25\%-28\% sand-very coarse, $10 \%-15 \%$ sand coarse and sand medium and $1 \%-5 \%$ sand fine and very fine. In contrast, the left side composed of $30 \%=37 \%$ sand coarse and sand fine and less than $10 \%$ for other substrates categories.

Table 1: The substrates weight $\%$ from downstream toward upstream

\begin{tabular}{|c|c|c|c|c|c|c|c|c|c|c|}
\hline \multirow{3}{*}{$\begin{array}{l}\begin{array}{l}\text { Sieve } \\
\text { size's } \\
(\mathbf{m m})\end{array} \\
\end{array}$} & \multirow{3}{*}{$\begin{array}{c}\text { Substrate Cat- } \\
\text { egory }\end{array}$} & \multicolumn{9}{|c|}{ Weight (\%) } \\
\hline & & \multicolumn{3}{|c|}{ Downstream } & \multicolumn{3}{|c|}{ Middle stream } & \multicolumn{3}{|c|}{ Upstream } \\
\hline & & Right & Middle & Left & Right & Middle & Left & Right & Middle & Left \\
\hline 2.36 & $\begin{array}{l}\text { Pebbles-Fine } \\
\text { granules }\end{array}$ & 0.44 & 0.32 & 0.05 & 0.44 & 0.32 & 0.04 & 0.43 & 0.32 & 0.04 \\
\hline 1.18 & $\begin{array}{l}\text { sand-very } \\
\text { coarse }\end{array}$ & 0.26 & 0.27 & 0.08 & 0.26 & 0.27 & 0.08 & 0.26 & 0.28 & 0.07 \\
\hline 0.71 & sand-coarse & 0.14 & 0.22 & 0.33 & 0.14 & 0.21 & 0.34 & 0.14 & 0.21 & 0.33 \\
\hline 0.5 & sand-medium & 0.10 & 0.09 & 0.11 & 0.10 & 0.09 & 0.11 & 0.10 & 0.09 & 0.12 \\
\hline 0.25 & sand-fine & 0.03 & 0.06 & 0.36 & 0.03 & 0.07 & 0.36 & 0.03 & 0.06 & 0.36 \\
\hline 0.125 & sand-very fine & 0.03 & 0.04 & 0.07 & 0.03 & 0.04 & 0.07 & 0.02 & 0.04 & 0.07 \\
\hline 0.045 & silt-coarse & 0.00 & 0.00 & 0.00 & 0.00 & 0.00 & 0.00 & 0.00 & 0.00 & 0.00 \\
\hline 0.02 & clay & 0.00 & 0.00 & 0.00 & 0.00 & 0.00 & 0.00 & 0.00 & 0.00 & 0.00 \\
\hline
\end{tabular}

\subsection{Water quality}

Table 2 showed the water quality of the river. There is no much difference for seven parameters measured. This river temperature ranges from $26-30^{\circ} \mathrm{C}$ with $\mathrm{pH}$ 6.4-7.2 and the salinity was less than 0.02 . C. fluminea could tolerate salinities ranging from $0 \%$ to $5 \%$ (9). The small size of $C$. fluminea experience little energy loss at lower $\left(4-11^{\circ} \mathrm{C}\right.$ and $\left.11-18^{\circ} \mathrm{C}\right)$ and upper $\left(25-32{ }^{\circ} \mathrm{C}\right)$ temperature ranges and is capable of performing seasonal compensation to maintain their capacity to survive in their range of temperature tolerance $((10)$. The water cloudiness measured in turbidity was less than $10 \mathrm{NTU}$, while nitrate measured less than $0.2 \mathrm{mg} / 1$ and DO concentration is less than $4 \mathrm{mg} / \mathrm{l}$. Based on NWQS standard, all parameter categorized this river as class I but DO concentration categorized this river as Class III at downstream and IV at upstream.

\subsection{Fluminea Collection And Length}

There was no $C$. fluminea recorded in upstream and downstream even though the substrate composition and size was no different with the middle part. This may be caused by the area was the best and easier spot for Etak harvesting by local communities compared to middle stream. Therefore, it was about 166 individuals of Etak had been collected at the middle stream with 77.3g. Figure 1 shows the length of Etak and the number of individuals collected in the middle stream of the river. Most of the collected Etak were length around $11.5-12.3 \mathrm{~mm}$. The highest abundance of Etak found was $11.9 \mathrm{~mm}$ in length. According to the John statement, $C$. fluminea can also be found at the substrates with higher fine granules but maybe in small length size as found at this study area range around 11-12 $\mathrm{mm}$ compared to the range of shell length for small size was mentioned in guideline $(19.310 \pm 1.137 \mathrm{~mm})$ by Xiao and Jiang (11). However, McMahon (12)stated that $C$. fluminea can live in a variety of substrates, but prefers sand and gravel, over silt hard surfaces.

It is also can be said that the collected $C$. fluminea was just past the juvenile phase. As mentioned in New York invasive species information (NYIS) (2012), juvenile clams can reach maturity about $6-10 \mathrm{~mm}$ in size for 3 to 6 months, and reach 10 to $30 \mathrm{~mm}$ in size during their first year. Besides that, the size of $\mathrm{C}$. fluminea was depending on food availability and temperatures. On the other hand, the increasing of substrate particles size will slow $C$. fluminea burrowing speed and impaired horizontal movement, especially the largest gravel. In addition, $C$. fluminea, was functioning as the filter feeder that can increase water clarity by removing broad quantities of planktonic food and fostering the distribution of macrophyte algae (7). This means they feed on small material suspended in water which easily to trap by small particles of substrates compared to larger substrates particles.

Table 2: Water quality of the river

\begin{tabular}{|l|l|c|}
\hline Station & \multicolumn{2}{|c|}{ Water quality parameter } \\
\hline Downstream & Conductivity $(\mu \mathrm{S} / \mathrm{cm})$ & 0.038 \\
\cline { 2 - 3 } & $\mathrm{pH}$ & 7.18 \\
\cline { 2 - 3 } & Temperature $\left({ }^{0} \mathrm{C}\right)$ & 29.23 \\
\cline { 2 - 3 } & Salinity $(\mathrm{Sal})$ & 0.01 \\
\cline { 2 - 3 } & DO $(\mathrm{mg} / \mathrm{l})$ & 3.52 \\
\cline { 2 - 3 } & Turbidity $(\mathrm{NTU})$ & 2.66 \\
\cline { 2 - 3 } & Nitrate $\left(\mathrm{mg} / \mathrm{l} \mathrm{NO}_{3}{ }^{-}\right)$ & 0.15 \\
\hline Middlestream & Conductivity $(\mu \mathrm{S} / \mathrm{cm})$ & 0.026 \\
\cline { 2 - 3 } & pH & 6.44 \\
\cline { 2 - 3 } & Temperature $\left({ }^{0} \mathrm{C}\right)$ & 28.95 \\
\cline { 2 - 3 } & Salinity $(\mathrm{Sal})$ & 0.01 \\
\cline { 2 - 3 } & DO $(\mathrm{mg} / \mathrm{l})$ & 3.71 \\
\cline { 2 - 3 } & Turbidity $(\mathrm{NTU})$ & 2.57 \\
\cline { 2 - 3 } & Nitrate $\left(\mathrm{mg} / 1 \mathrm{NO}{ }^{-}\right)$ & 0.14 \\
\hline Upstream & Conductivity $(\mu \mathrm{S} / \mathrm{cm})$ & 0.038 \\
\cline { 2 - 3 } & pH & 6.59 \\
\hline
\end{tabular}




\begin{tabular}{|l|l|c|}
\hline \multirow{4}{*}{} & Temperature $\left({ }^{0} \mathrm{C}\right)$ & 26.26 \\
\cline { 2 - 3 } & Salinity $(\mathrm{Sal})$ & 0.02 \\
\cline { 2 - 3 } & DO $(\mathrm{mg} / \mathrm{l})$ & 2.54 \\
\cline { 2 - 3 } & Turbidity $(\mathrm{NTU})$ & 2.06 \\
\cline { 2 - 3 } & Nitrate $\left(\mathrm{mg} / \mathrm{l} \mathrm{NO}_{3}{ }^{-}\right)$ & 0.1 \\
\hline & & \\
\hline
\end{tabular}

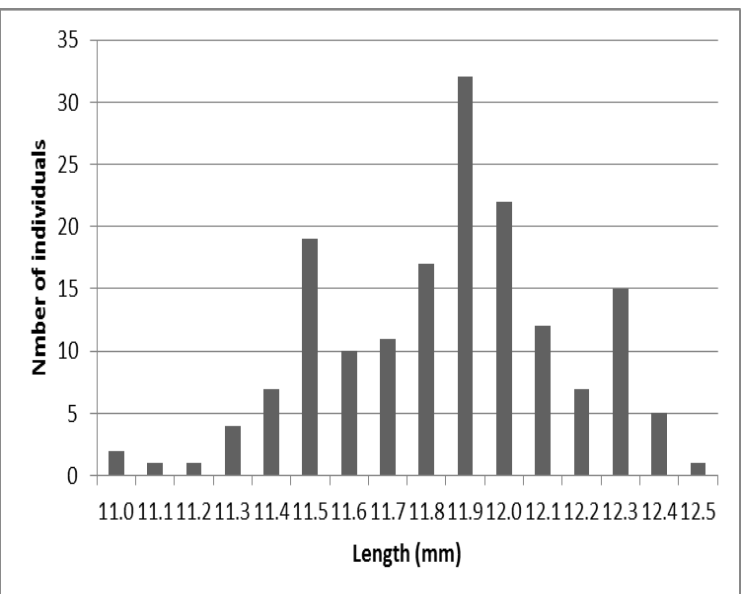

Fig. 1: The length of Etak and the number of individuals collected at the middle stream of the river.

\section{Conclusion}

The result from water quality analysis showed there was no big different among the six parameters used for water quality as well as substrates composition. Meanwhile, Gunung Reng River was not polluted by any pollution that could cause low result in water analysis except for DO concentration at downstream was lower than $2 \mathrm{mg} / \mathrm{l}$. However, the Etak was only found and collected at the middle stream. Meanwhile, the collected Etak were found more with length around $11.5-12.3 \mathrm{~mm}$. This was believed to be due to the substrates type and food availability in the area. Besides the area was the spot for Etak harvesting which may lead to the small size as the clams had not enough time to develop to the larger size.

\section{Acknowledgement}

We are grateful to the Ministry of Higher Education for sponsoring this research work by the Trans Disciplinary Research Grant
Scheme (TRGS; R/TRGS/A08.00/00244A/005/2016/000389). We are also thankful to the management Universiti Malaysia Kelantan for lending the lab instruments for the completion of this research.

\section{References}

[1] Kramer-Welt. Aquatic Invasion Ecology Fall 2008 Corbicula fluminea (O F Müller, 1774) - Asian Clam 2008.

[2] Aweng ER. Water Quality and Shellfish Related Gastrointestinal Disease Cases in Kota Bharu. Malaysia: Universiti Teknologi Malaysia; 2006.

[3] Nasarudin MHM, Bahar AMA. River tourism: A potential in Pergau River, Jeli, Kelantan Universiti Malaysia Kelantan2012.

[4] John. Corbicula fluminea (Asian Clam) in the Roanoke River, North Carolina: A Stresses Population? . Cooper Environmental Research. 2007:413-34

[5] Castaneda. Physical factors affecting the invasion success of the Asian clam (C. fluminea): A global synthesis.: McGill University, Montreal, Redpath Museum; 2012.

[6] Crepso, Dolbeth, Anastacio. Predicting global habitat suitability for Corbicula fluminea using species distribution models: The importance of different environmental datasets. Ecological Modelling. Araujo, Moreno, \&Ramos.(1993). The Asiatic clam Corbicula fluminea (Muller, 1774) (bivalvia:corbiculidae) in Europe. . Amerological Bulletionivan Malac. 2015;10(1).

[7] Simard, Martel, Blier. North American range extension of the invasive Asian clam in a St. Lawrence River power station thermal plume. Range extension of the invasive Asian clam,. 2012; 7(1 ):81-9, 1-10.

[8] Araujo, Moreno, Ramos. The Asiatic clam Corbicula fluminea (Muller, 1774) (bivalvia:corbiculidae) in Europe. . Amerological Bulletionivan Malac. 1993;10(1).

[9] Sousa R, Antunes C, Guilhermino L. Ecology of the invasive Asian clam Corbicula fluminea (Müller, 1774) in aquatic ecosystems: an overview. Ann Limnol. 2008; 44(2):85-94.

[10] Saucedo PE, Ocampo L, Monteforte M, Bervera H. Effect of temperature on oxygen consumption and ammonia excretion in the Calafia mother-of-pearl oyster, Pinctada mazatlanica (Hanley, 1856). . Aquaculture. 2004;229(1-4):377-87.

[11] Xiao L, Jiang C. Effect of Temperature and Salinity on the Metabolic Rate of the Asiatic clam Corbicula fluminea (Muller, 1774). Springer Plus a Springer Open Journal 2014;1-9.

[12] McMahon. Invasive characteristics of the freshwater bivalve, Corbicula Fluminea. Nonindigenous freshwater organism:vectors, biology and impacts1999. 315-46 p. 